\title{
Dimensionamento de leitos de secagem de lodo de estações de tratamento de água com emprego de modelos probabilísticos
}

\section{Design of sludge drying beds of water treatment plants using probabilistic modeling}

\author{
Data de entrada: \\ 05/07/2015 \\ - Data de aprovação: \\ 29/12/2015
}

Vivian Ane Lopes Cabral / Demétrius Brito Viana / Rafael Kopschitz Xavier Bastos

\section{Resumo}

Apresenta-se neste trabalho um exercício de dimensionamento de leito de secagem de lodo de decantador de estação de tratamento de água (ETA) com emprego de modelagem probabilística. Nesta abordagem são consideradas incertezas associadas às variáveis de entrada do modelo de dimensionamento: vazão, turbidez da água bruta, dose de sulfato de alumínio e concentração de sólidos no lodo armazenado no decantador (dados primários de controle operacional da ETA da Universidade Federal de Viçosa - UFV); densidade de sólidos no lodo, altura da camada de lodo no leito e concentração de sólidos na torta (dados de literatura). Foram testados três cenários: três, seis e doze meses de armazenamento do lodo no decantador. As estimativas de volume de lodo acumulado no decantador e, por conseguinte, as de demanda de área para o leito de secagem, não foram elevadas e não foram observadas grandes diferenças entre os três cenários considerados. Em decorrência da modelagem probabilística os resultados de demanda de área são expressos em termos de distribuição de probabilidades e discutidos em termos de escolhas envolvendo margem de segurança e custos associados a eventuais sub ou superdimensionamento.

Palavras-chave: leito de secagem, lodo de ETA, modelagem probabilística.

\section{Abstract}

This paper presents a designing exercise of a water treatment plant (WTP) sludge drying bed using probabilistic modeling. Such an approach takes into account uncertainties associated with the input variables of the design models: flow rate, raw water turbidity, aluminum sulfate dose and the sludge solids concentration (primary data from the operational control of the University of Viçosa WTP); sludge solids density; sludge depth in the drying bed, and the dried sludge solids concentration (literature data). Three scenarios were assessed: three, six and twelve months of sludge storing in the settling tank. The estimates of the sludge volumes accumulated in the settling tank, thus of the required drying bed area, were not high and no large differences between the three scenarios were noticed. With probabilistic modeling, the results of land area requirements are expressed in terms of probability distribution and were discussed based on choices involving safety margins and costs associated with possible under- or overdesigning.

Keywords: Sludge drying beds. WTP sludge. Probabilistic modeling. 
Vivian Ane Lopes Cabral - Engenheira ambiental. Doutoranda em Engenharia Civil pela Universidade Federal de Viçosa."

Demétrius Brito Viana - Engenheiro ambiental. Mestre em Engenharia Civil pela Universidade Federal de Viçosa. Engenheiro da Fundação Nacional de Saúde.

Rafael Kopschitz Xavier Bastos - Engenheiro Civil pela Universidade Federal de Juiz de Fora. PhD em Engenharia Sanitária pela University of Leeds. Professor do Departamento de Engenharia Civil da Universidade Federal de Viçosa.

* Endereço para correspondência: Universidade Federal de Viçosa. Departamento de Engenharia Civil. Viçosa-MG. CEP 36570-000. Telefone: (31) 3899 2356. Fax: (31) 3899-1481. E-mail: ane.cabralayahoo.com.br.

\section{INTRODUÇÃO}

O tratamento do lodo de Estações de Tratamento de Água (ETAs) visa, basicamente, à remoção de água, de forma a viabilizar o transporte e a disposição final do resíduo. Para tanto, podem ser utilizados sistemas naturais, como lagoas de lodo e leitos de secagem, ou processos mecanizados, como centrífugas e filtros-prensa. Os processos naturais possuem grande potencial de aplicação onde haja condições climáticas favoráveis e disponibilidade de área. Comparativamente às lagoas de lodo, os leitos de secagem apresentam como vantagens a obtenção, em menor tempo, de torta de lodo desidratado com maior concentração de sólidos, além de operação e manutenção mais fáceis (REALI, 1999).

O dimensionamento de leitos de secagem de lodo de ETA não é normatizado. Usualmente, são adotadas abordagens tão simples quanto a estimativa da área necessária com base no volume e na altura do lodo a ser mantido no leito de secagem (ou da taxa de aplicação de sólidos por unidade de área, em kg.m²) (RICHTER, 2001). Entretanto, para isso, é preciso que se disponha de dados de produção de massa de sólidos por volume de água tratada. Idealmente, tal informação deve advir de medições de campo e do cômputo de balanço de massa ao longo da ETA. Na ausência dessas informações, pode-se recorrer a modelos preditivos empíricos que relacionem a produção de sólidos com as características da água e do tratamento empregado.

No entanto, nessa abordagem, como em qualquer modelo preditivo, incertezas em torno das variáveis de entrada são propagadas pelo modelo e se fazem refletir na variável resposta, podendo, por fim, comprometer a confiabilidade do projeto. Nos chamados modelos determinísticos, as variáveis de entrada são assumidas em valores únicos e, por conseguinte, a resposta é também expressa por meio de um único valor, sujeito a sub ou superestimativas. Assim, é preciso critério na definição dos valores das variáveis de entrada, como, por exemplo, valores típicos ou médios. Alternativamente, a modelagem probabilística (estocástica) permite considerar incertezas (incerteza propriamente dita e variabilidade) ${ }^{1}$ associadas ou inerentes a cada variável de entrada. Nessa abordagem, as variáveis de entrada são descritas em intervalos de valores e de acordo com determinada distribuição de probabilidades, a propagação das incertezas pelo modelo é realizada por meio de técnicas de amostragem aleatória e, por conseguinte, os resultados também são expressos em termos de distribuição de probabilidades (MORGAN; HENRION, 2003). Isso proporciona flexibilidade na tomada de decisão, ou seja, permite cotejar aspectos técnicos e econômicos para a solução final.

Com tal abordagem, apresenta-se neste trabalho um exercício de dimensionamento de leitos de secagem para desaguamento do lodo do decantador da Estação de Tratamento de Água da Universidade Federal de Viçosa (ETA UFV).

\footnotetext{
1 A incerteza verdadeira decorre do desconhecimento do comportamento de determinada variável, processo ou fenômeno que se quer modelar e, por conseguinte, pode ser reduzida por meio de investigação, como, por exemplo, monitoramento. A variabilidade expressa um comportamento intrínseco a uma variável, processo ou fenômeno, atribuível à heterogeneidade ou diversidade natural; assim, não pode ser reduzida por meio de investigação, apenas mais bem conhecida e descrita (MORGAN; HENRION, 2007).
} 


\section{METODOLOGIA}

Para a estimativa da produção de sólidos, foi utilizado o modelo empírico para ETAs que empregam sulfato de alumínio como coagulante, expresso na Equação 1 (KAWAMURA, 1991 apud REALI, 1999). A estimativa se faz em termos de massa de sólidos sedimentados por $\mathrm{m}^{3}$ de água tratada num determinado período de acúmulo de lodo no decantador em função da turbidez da água bruta e da dose de coagulante aplicada. Considerou-se neste trabalho que toda a massa de sólidos gerados na ETA UFV seria acumulada na etapa de decantação.

Equação 1: $M s=\frac{\left(\mathrm{k}_{1} D+\mathrm{k}_{2} T\right)}{1000} \times \mathrm{Q} \times \mathrm{t}$

Em que:

- $M s=$ produção de sólidos $\left(\mathrm{kg}\right.$ de sólidos por $\mathrm{m}^{3}$ de água tratada);

- $D=$ dose de sulfato de alumínio $\left(\mathrm{mg} \mathrm{L}^{-1}\right)$;

- $\quad T$ = turbidez da água bruta (UT);

- $\quad Q$ = vazão de água tratada $\left(\mathrm{m}^{3} \mathrm{~s}^{-1}\right)$;

- $\quad t=$ período de acúmulo de lodo (s);

- $\quad K_{1}=$ relação estequiométrica entre a dose de coagulante e a formação do precipitado de hidróxido (adimensional);

- $K_{2}=$ relação entre sólidos suspensos totais e turbidez (adimensional).

A partir da estimativa da massa de sólidos armazenada no decantador, é possível estimar a massa de lodo correspondente em função da concentração de sólidos esperada no lodo, bem como o volume de lodo, considerando uma dada densidade (Equações 2 e 3). Para a estimativa da densidade do lodo, utilizou-se a equação apresentada por Richter (2001), em função da concentração de sólidos esperada no lodo, da densidade dos sólidos esperada e da densidade da água (Equação 4). 0 cálculo da área da unidade de desaguamento de lodo, neste caso, um leito de secagem convencional, é baseado no volume de lodo a desaguar e na altura da camada de lodo no leito (Equação 5).

Equação 2: $M_{L}=M s / C$

Equação 3: $V_{L}=M_{L} / \delta_{L}$

Equação 4: $\delta_{L}=\left[1 /\left(C / \delta_{S}\right)\right]+[(1-C) / \delta]$

Equação 5: $A=V_{L} / h$

Em que:

- $M_{L}=$ estimativa da massa de lodo gerada;

- $M_{S}=$ massa de sólidos estimada;

- $\quad C=$ concentração de sólidos esperada no lodo;

- $\quad V_{L}=$ volume de lodo

- $\quad \delta_{S}=$ densidade dos sólidos esperada no lodo;

- $\delta=$ densidade da água, considerada igual a $1.000 \mathrm{~kg} / \mathrm{m}^{3}$;

- $\delta_{L}=$ densidade do lodo;

- $A$ = área do leito de secagem;

- $h=$ altura de lodo no leito de secagem.

Para o ajuste de funções densidade de probabilidades às variáveis "turbidez da água bruta", "dose de coagulante" e "vazão da ETA", foi utilizado o banco de dados de quatro anos de monitoramento horário da ETA UFV. Para testar a aderência das séries de dados a funções densidade de probabilidades, foram utilizados os testes Qui-quadrado $\left(x^{2}\right)$, Kolmogorov Smirnov (KS), Anderson Darling (AD), 
além do gráfico de probabilidades. Para as variáveis sobre as quais não se dispunha de séries de dados, foram adotadas faixas de valores (com base em informações da literatura, em dados pontuais de concentração de sólidos e de densidade dos sólidos do lodo da ETA UFV $\pm 25 \%$ e em valores típicos de vazão de água tratada na estação) e distribuições uniformes ou triangulares. A distribuição uniforme se apresenta como opção apropriada quando se é capaz de identificar intervalos de valores possíveis de ser assumidos pela variável em questão, mas não a probabilidade de ocorrência de valores intermediários entre o mínimo e o máximo. A distribuição triangular pode ser entendida como uma representação conservadora da distribuição normal, portanto, cujos valores intermediários têm maior probabilidade de ocorrência que os extremos, mas envolvendo elevado grau de incerteza. Como indicado por Morgan e Henrion (2003), a opção por essas duas distribuições, apesar de simples e um tanto arbitrárias, pode ser conveniente quando o comportamento de uma variável não é bem conhecido e contribui para evitar interpretações demasiada e injustificadamente detalhadas dos resultados de um modelo.

Os modelos expressos nas Equações 1 a 5 foram simulados por meio de 10.000 iterações, com emprego da técnica de amostragem aleatória (das variáveis de entrada dos modelos) de hipercubos latinos. Todos esses testes e simulações foram feitos com o programa aRisk versão 5.5 (Palisade Corporation). Os resultados obtidos das simulações no aRiskforam expressos pormeio de histogramas de frequência, considerando três períodos de acúmulo de lodo no decantador: três, seis e 12 meses. Ovolume de lodo acumulado no decantador em cada período e, assim, o volume a ser desaguado no leito de secagem foram comparados, a fim de subsidiar a decisão sobre intervalos entre limpezas do decantador.

Adicionalmente, por meio de análise de sensibilidade, procurou-se identificar as variáveis de entrada cujas variações mais nitidamente influenciaram a variação da resposta "área para desaguamento em leitos de secagem". Para isso, utilizou-se o coeficiente de correlação de Spearman, ou posto-ordem $r_{s}$ de Spearman, que é uma medida não paramétrica e, portanto, independente do tipo de distribuição das variáveis. Nesse teste, os coeficientes determinam a probabilidade associada com a ocorrência de correlação entre uma dada variável de entrada e a de saída, utilizando rankings de valores e não os valores em si (como no caso do coeficiente de correlação linear) - variam entre -1 e 1 , sendo que, quanto mais próximo de zero, menor a correlação entre as variáveis e, quanto mais distante de zero (próximo a -1 ou 1), maior a correlação. Enfim, quanto mais alta a correlação entre uma variável de entrada e a de saída, mais importante a variável de entrada na determinação do valor de saída (SPIEGEL, 1993).

\section{RESULTADOS E DISCUSSÃO}

As faixas de valores e as funções densidade de probabilidades adotadas para cada variável utilizada no dimensionamento do leito de secagem, além dos parâmetros que definem essas funções, estão apresentadas na Tabela 1. A Tabela 2 apresenta os resultados da previsão da massa de sólidos e de lodo acumulada no decantador para os três períodos analisados, em termos da mediana e do percentil 95 das distribuições de frequência resultantes. Na Figura 1, apresentam-se os histogramas de distribuição de probabilidades das estimativas de massa de sólidos e de lodo para os períodos avaliados. 
Tabela 1 - Variáveis de entrada utilizadas no dimensionamento do leito de secagem da ETA UFV e respectivas distribuições de probabilidades.

\begin{tabular}{|c|c|c|c|c|c|}
\hline Variável de entrada & Distribuição & Fonte & $\begin{array}{l}\text { Média } \pm \text { desvio padrão }{ }^{5} \text { ou } \\
\text { valor mais provável }{ }^{6}\end{array}$ & Mín. & Máx. \\
\hline Turbidez da água bruta (UT) & Log normal & ETA UFV $^{1}$ & $19,07 \pm 22,22$ & - & - \\
\hline $\begin{array}{c}\text { Dose de coagulante } \\
\left(\mathrm{mg} \mathrm{L}^{-1}\right)\end{array}$ & Log logística & ETA UFV ${ }^{1}$ & $3,95 \pm 9,28$ & - & - \\
\hline $\operatorname{Vazão}\left(L^{-1}\right)$ & Triangular & ETA UFV ${ }^{1}$ & $50^{5}$ & 40 & 70 \\
\hline $\mathrm{K}_{1}$ & Uniforme & Literatura $^{2}$ & - & 0,23 & 0,26 \\
\hline $\mathrm{K}_{2}$ & Uniforme & Literatura $^{2}$ & - & 1,0 & 2,0 \\
\hline $\begin{array}{c}\text { Concentração de sólidos no lodo - } \\
3 \text { meses (\%) }\end{array}$ & Uniforme & ETA UFV $^{3}$ & - & 1,5 & 2,5 \\
\hline $\begin{array}{c}\text { Concentração de sólidos no lodo - } \\
6 \text { meses (\%) }\end{array}$ & Uniforme & ETA UFV $^{3}$ & - & 2,9 & 4,8 \\
\hline $\begin{array}{l}\text { Concentração de sólidos no lodo - } \\
12 \text { meses (\%) }\end{array}$ & Uniforme & ETA UFV $^{3}$ & - & 4,5 & 7,5 \\
\hline Densidade dos sólidos $\left(\mathrm{kg} \mathrm{m}^{-3}\right)$ & Uniforme & ETA UFV $^{3}$ Literatura $^{4}$ & - & 1.700 & 2.300 \\
\hline Altura da camada de lodo no leito $(\mathrm{m})$ & Uniforme & Literatura $^{2}$ & - & 0,2 & 0,6 \\
\hline Concentração de sólidos na torta (\%) & Uniforme & Literatura $^{2}$ & - & 20 & 25 \\
\hline
\end{tabular}

Notas: ${ }^{1}$ Dados horários, janeiro de 2005 a fevereiro de $2011 .{ }^{2}$ Reali (1999). ${ }^{3}$ Dados pontuais $\pm 25 \%$ (margem de segurança). ${ }^{4}$ Richter (2001). ${ }^{5}$ Parâmetros que definem as distribuições. ${ }^{6}$ Valor com maior incidência no banco de dados.

Tabela 2 - Estimativas da massa $(\mathrm{kg})$ de sólidos e de lodo armazenados no decantador da ETA UFV ao longo de três, seis e 12 meses - medianas e do percentil 95.

\begin{tabular}{|c|c|c|c|}
\hline \multirow{2}{*}{ Período de acúmulo no decantador } & Variável estimada & Mediana & \multicolumn{1}{c|}{$\mathbf{9 5 \%}$} \\
\hline \multirow{2}{*}{3 meses } & Massa de sólidos & $2.058,4$ & $228.123,2$ \\
\hline \multirow{2}{*}{6 meses } & Massa de lodo & $103.945,7$ & 8.661 \\
\cline { 2 - 4 } & Massa de sólidos & 4.579 & $233.381,7$ \\
\hline \multirow{2}{*}{12 meses } & Massa de lodo & $107.522,2$ & $17.562,6$ \\
\hline & Massa de sólidos & 8.348 & $309.403,6$ \\
\hline
\end{tabular}


Figura 1 - Histogramas de distribuição de probabilidade das estimativas de massa de sólidos e de lodo armazenados no decantador da ETA UFV ao longo de: (a) três, (b) seis e (c) 12 meses.
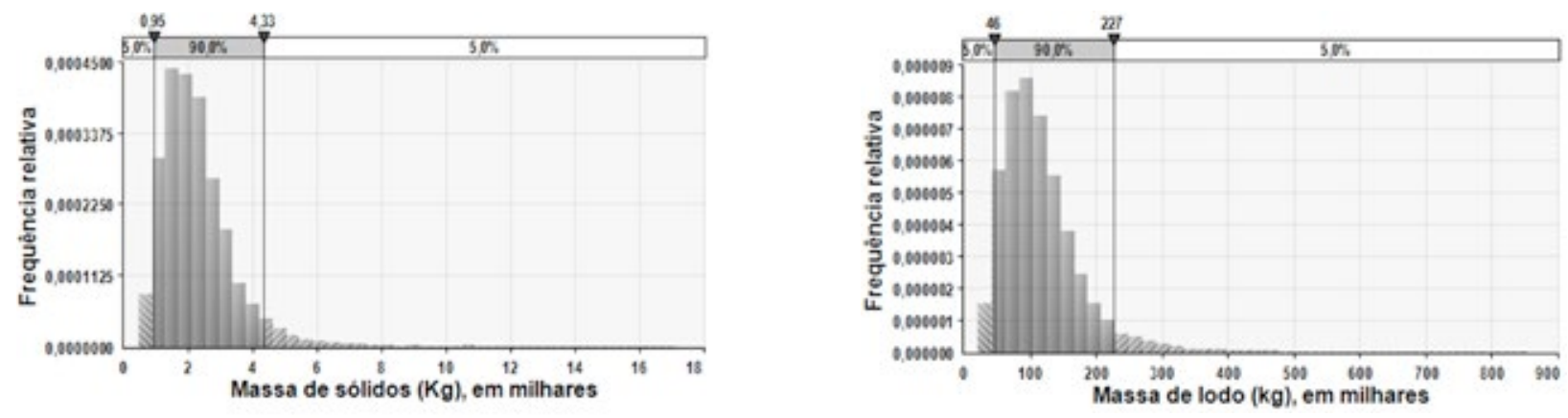

(a)
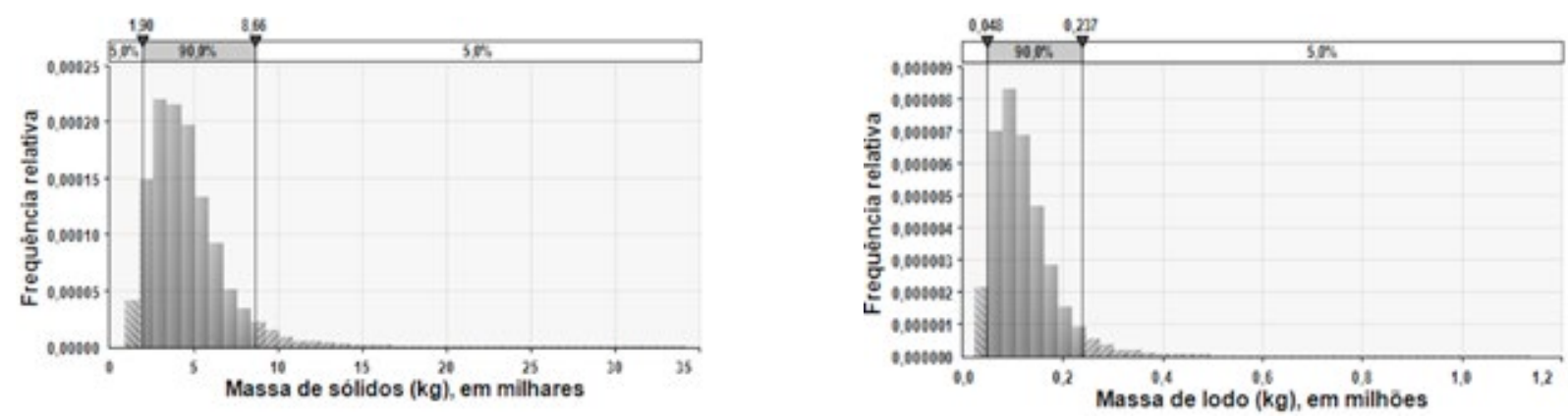

(b)
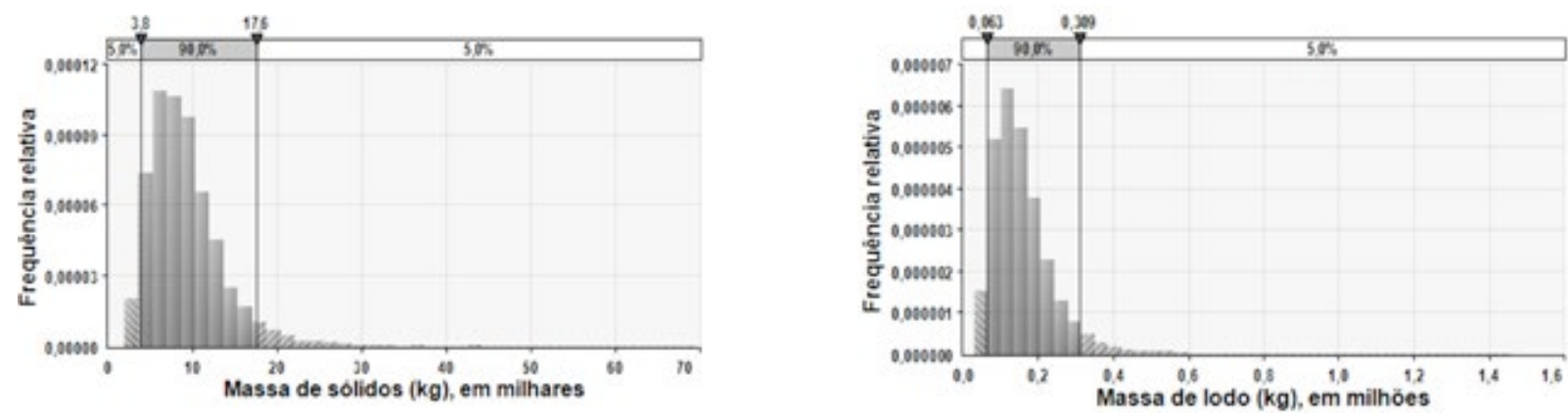

(c)

Comparadas com valores obtidos em outros estudos (SARON; LEITE, 2003; SOUZA; CORDEIRO, 2005), as estimativas efetuadas indicam geração de sólidos relativamente baixa na ETA UFV. Isso se deve, certamente, à turbidez predominantemente baixa da água bruta (mediana de 9,3 uT), pois a estimativa de sólidos se baseia na turbidez da água bruta e na dose de coagulante empregada, estando essas duas variáveis relacionadas positivamente (quando a turbidez da água bruta aumenta, em geral, dosa-se mais coagulante para o tratamento da água). A ETA UFV é de pequeno

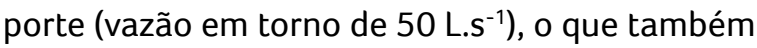
ajuda a explicar as baixas estimativas de massa 
de sólidos acumulada no decantador para os três períodos analisados. Naturalmente, a massa de sólidos acumulada no decantador aumenta (consideravelmente) com o passar do tempo, à medida que aumenta o volume total de água tratada.

Em termos de massa de lodo úmido acumulada no decantador, o comportamento é diferente. Ocorre, sim, incremento ao longo do tempo, porém é bem mais discreto do que o observado para a massa de sólidos, devido ao adensamento natu- ral do lodo mantido no interior do decantador por longos períodos de tempo. Em resumo, as estimativas de massa de lodo acumulada ao longo dos três períodos considerados (três, seis e 12 meses) não diferiram tanto entre si.

Com base nas estimativas de densidade (Figura 2) e de massa de lodo acumulada no decantador, foram feitas estimativas de volume de lodo a ser descartado do decantador e encaminhado para processos de desaguamento (Tabela 3 e Figura 3).

Figura 2 - Histogramas de distribuição de probabilidade das estimativas de densidade do lodo armazenado no decantador da ETA UFV ao longo de (a) três, (b) seis e (c) 12 meses.
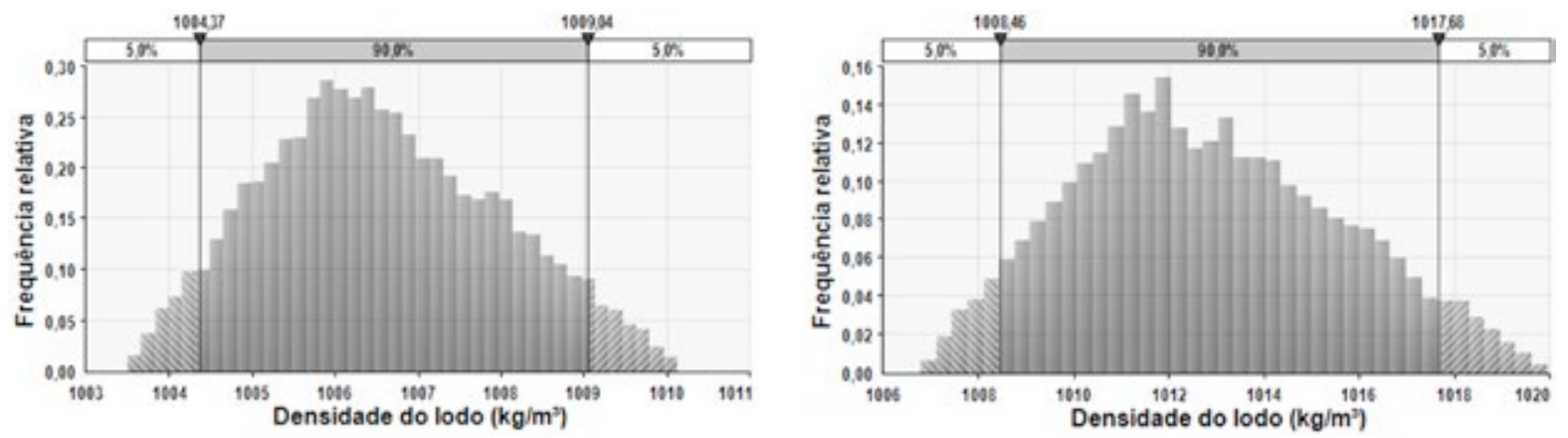

(a)

(b)

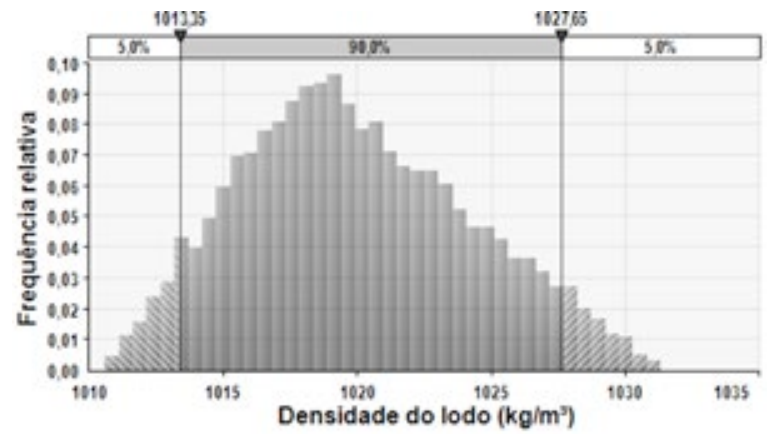


Tabela 3 - Estimativa do volume de lodo $\left(\mathrm{m}^{3}\right)$ armazenado no decantador da ETA UFV ao longo de três, seis e 12 meses (medianas e percentis 95).

\begin{tabular}{|l|c|c|}
\hline Período & Mediana & \\
\hline 3 meses & 104 & 226 \\
\hline 6 meses & 106 & 231 \\
\hline 12 meses & 138 & 304 \\
\hline
\end{tabular}
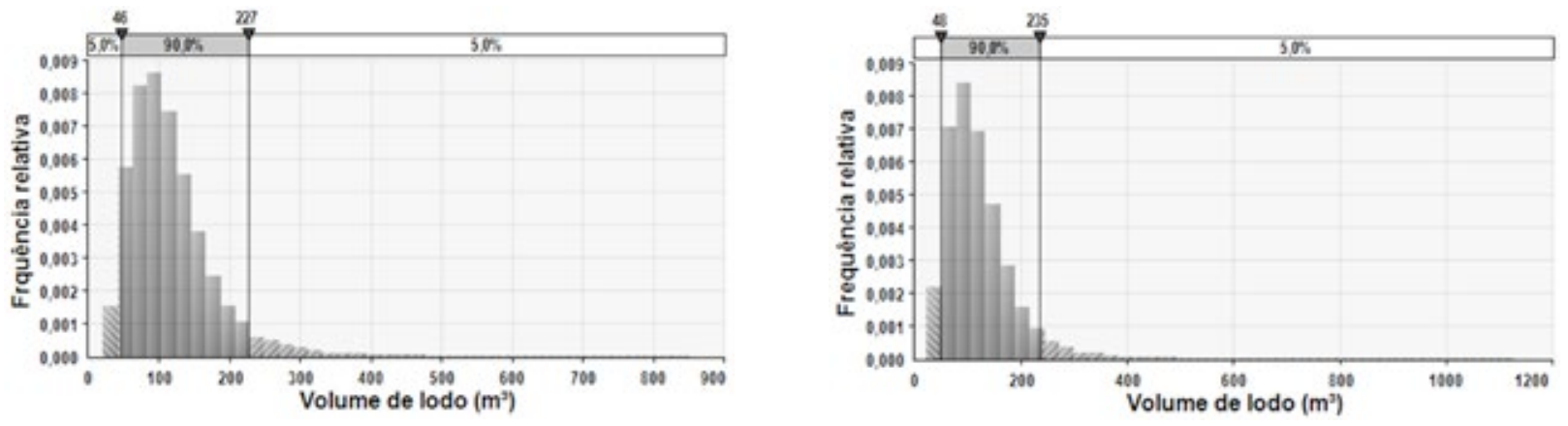

(a)

(b)

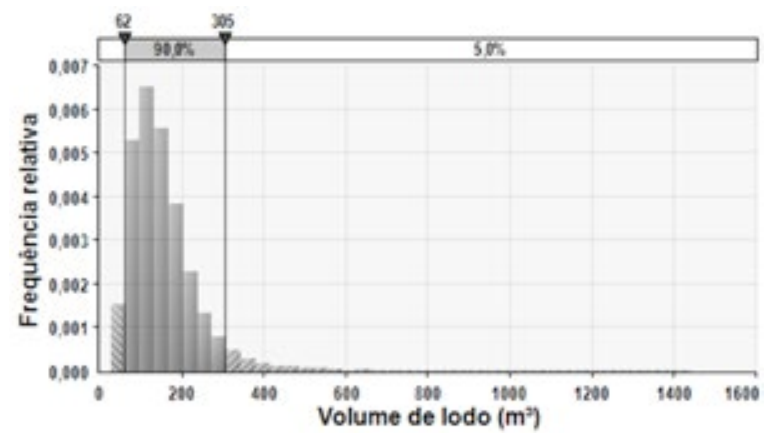

(c)

Figura 3 - Histogramas de distribuição de probabilidade das estimativas do volume de lodo armazenado no decantador da ETA UFV ao longo de (a) três, (b) seis e (c) 12 meses.

Verifica-se que as estimativas de volume de lodo acumulado no decantador não são altas, inclusive, sem grandes diferenças entre os três períodos considerados, resultado do aumento apenas discreto da massa de lodo de um período para outro. Como já comentado, isso se deve ao incremento da concentração de sólidos e, por outro lado, ao decréscimo da massa de água do lodo. Nota-se que praticamente não há diferenças entre as estimativas de volume de lodo gerado em três e seis meses de operação da ETA UFV, porque a concentração de sólidos esperada para seis meses é praticamente o dobro da de três meses. Mesmo quando se considera o período de um ano, o incremento de volume de lodo acumulado não é tão elevado (em torno de $30 \%$, se tomadas as medianas como referência).

Em resumo, esses resultados sugerem que as operações de limpeza do decantador da ETA UFV po- 
dem se dar em intervalos relativamente longos, sem que isso represente grande aumento de volume de lodo armazenado e, portanto, de demanda de área para implantação de unidade de desaguamento de lodo. Acredita-se que a adoção de intervalos mais longos deve, inclusive, favorecer o próprio processo de desaguamento, devido ao adensamento do lodo no decantador - dependendo do tempo de armazenamento, o decantador passa a funcionar como um decantador-adensador. Com efeito, isso foi verificado durante experimento de desaguamento de lodo da ETA UFV em leito-piloto de secagem: o lodo retirado do decantador com período de retenção de 12 meses apresentou concentração de sólidos de 6,5\% (BATISTA; CABRAL, 2011). Tais condições, como citado por Richter (2001), além de minimizar a área necessária ao desaguamento, diminuem o tempo de secagem do lodo no leito. Contudo, como adverte Reali (1999), essa situação favorece o surgimento de condições anaeróbias no lodo, o que pode comprometer a qualidade da água tratada, devido à dissolução de metais presentes no lodo (por exemplo, $\mathrm{Fe}, \mathrm{Mn}$, Al e metais pesados).

A Figura 4 apresenta os resultados de previsão de demanda de área para implantação de leitos de secagem para desaguamento dos volumes estimados de lodo: distribuições de probabilidade resultantes nos três cenários considerados para o acúmulo de lodo no decantador - três, seis e 12 meses. Na Tabela 4, os resultados são resumidos em termos das medianas e percentis 95 das distribuições de probabilidade.
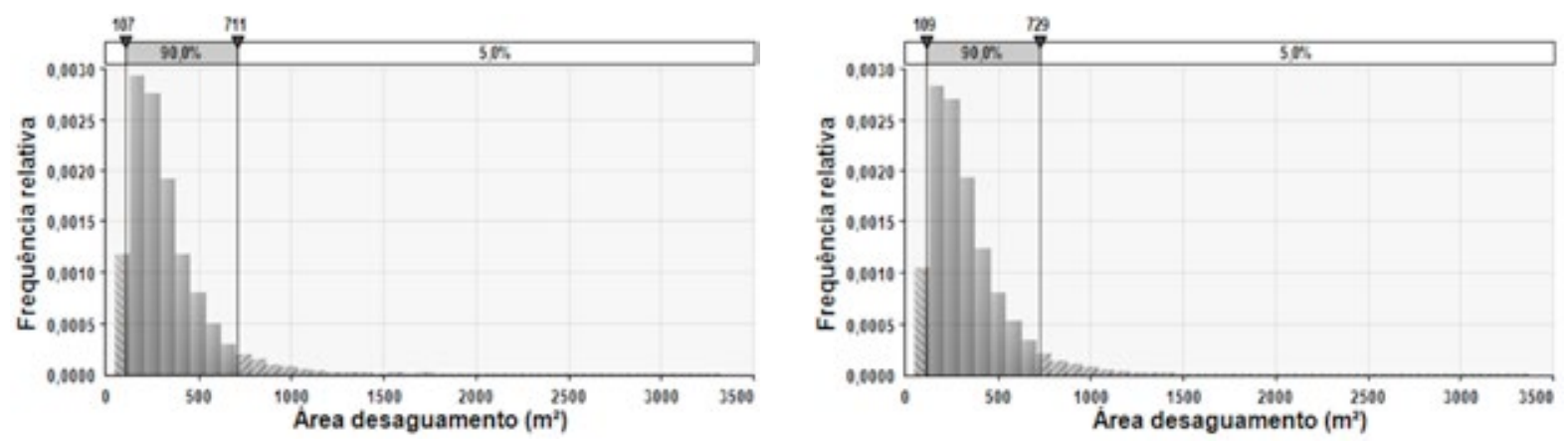

(a)

(b)

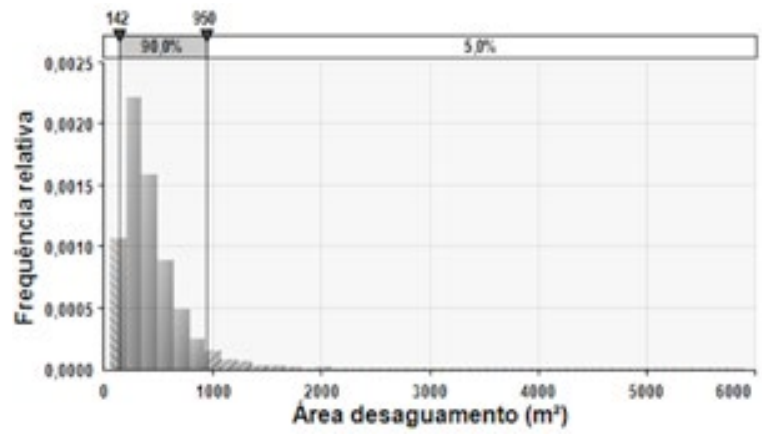

(c)

Figura 4 - Histogramas de distribuição de probabilidade das estimativas da área de leitos de secagem necessária ao desaguamento do lodo armazenado no decantador da ETA UFV ao longo de (a) três (b), seis e (c) 12 meses. 
Tabela 4 - Estimativa da demanda de área $\left(\mathrm{m}^{2}\right)$ de leitos de secagem para desaguamento do lodo armazenado no decantador da ETA UFV ao longo de três, seis e 12 meses - medianas e percentis 95.

\begin{tabular}{|c|c|c|}
\hline Período de acúmulo & Mediana & $95 \%$ \\
\hline 3 meses & 268,7 & 690,2 \\
\hline 6 meses & 274,6 & 716,9 \\
\hline 12 meses & 356,9 & 930,4 \\
\hline
\end{tabular}

As estimativas de demanda de área não foram elevadas. Mesmo tomando como referência o valor do percentil 95 referente a 12 meses de armazenamento de lodo no decantador, a estimativa de área necessária é inferior à sugerida por Richter (2001) como limite prático para utilização do leito de secagem como unidade de desaguamento do lodo $\left(1.500 \mathrm{~m}^{2}\right)$. A opção pelo valor do percentil 95 constituiria solução com margem de segurança, porém conservadora, ou seja, considerando os parâmetros de projeto e as incertezas em torno destes parâmetros, a probabilidade de que a área adotada se mostre insuficiente seria de apenas $5 \%$. Na prática, essa solução pode representar superdimensionamento da unidade e, consequentemente, aumento desnecessário de custos. A adoção da mediana implica redução acentuada de área (mais de 60\%) e, assim, economia na construção, porém a segurança do dimensionamento se vê diminuída. Entretanto, o eventual subdimensionamento do leito de secagem resultaria apenas em taxa de aplicação de sólidos acima do previsto e em consequências como aumento do tempo de desaguamento do lodo e/ou produção de torta menos desidratada.

$\mathrm{Na}$ Tabela 5, estão apresentados os resultados do teste de correlação não paramétrica de Spearman utilizado para análise de sensibilidade da simulação, ou seja, para avaliar quanto a variação das variáveis de entrada influenciou na variação da resposta - área necessária para o desaguamento do lodo gerado.

Tabela 5 - Coeficiente de correlação de Spearman entre as variáveis de entrada do modelo de dimensionamento dos leitos de secagem e a variável resposta - área necessária para desaguamento do lodo.

\begin{tabular}{|c|c|}
\hline Variável de entrada' & Correlação de Spearman \\
\hline Altura do leito & $-0,60$ \\
\hline Turbidez da água bruta & 0,44 \\
\hline Dose de coagulante & 0,41 \\
\hline$K_{2}$ & 0,30 \\
\hline Concentração de sólidos no lodo & $-0,28$ \\
\hline Vazão & 0,26 \\
\hline Densidade dos sólidos & $-0,01$ \\
\hline
\end{tabular}

Nota: ${ }^{1}$ Ordenadas em ordem decrescente do coeficiente de Spearman. 
A altura da camada de lodo no interior do leito foi a variável que mais impactou a variação da resposta (área dos leitos de secagem), naturalmente com relação inversa, isto é, quanto maior a altura de lodo, menor a demanda de área. Na Equação 5, nota-se que, uma vez estimado o volume de lodo (com todas as incertezas envolvidas), a área dos leitos de secagem depende somente da altura de lodo no leito. Como critério de projeto, poderia ter sido adotado valor único para a altura da camada de lodo no leito, mas optou-se por assumir faixas de valores $(0,2-0,6 \mathrm{~m})$ que respondessem por variações (incertezas) operacionais no descarte do lodo. Por outro lado, conforme já discutido, a própria decisão final sobre a área dos leitos a ser adotada (por exemplo, se baseada na mediana ou no percentil 95) irá se refletir na altura de lodo. Em resumo, essa será uma decisão de projeto: espessuras menores da camada de lodo implicam áreas maiores para desaguamento do lodo e menores taxas de aplicação de sólidos, demandam menor tempo de secagem ou, para um mesmo tempo, alcançam teor de sólidos mais elevado; isso, comparativamente às camadas de lodo mais profundas, quando se opta pela menor área e, consequentemente, maior taxa de aplicação de sólidos.

A turbidez da água bruta e a dose de coagulante (variáveis correlacionadas entre si, diga-se de passagem), nessa ordem, revelaram-se também ser importantes na determinação da área dos leitos de secagem. Esses são dados de monitoramento da ETA em questão, sobre os quais foram ajustadas funções densidade de probabilidades. Portanto, as incertezas aqui são devidas à variabilidade, intrínsecas a essas variáveis. Isso revela a importância da disponibilidade de bancos de dados robustos e confiáveis sobre turbidez da água bruta e dose de coagulante para a previsão das áreas de leitos de secagem utilizando modelos empíricos, bem como da sua caracterização estatística adequada.

$\mathrm{O}$ coeficiente $\mathrm{K}_{2}$, que expressa a relação entre sólidos suspensos totais e turbidez da água bruta, utilizada na estimativa de produção de massa de sólidos (Ms) - $\mathrm{kg}$ de sólidos por $\mathrm{m}^{3}$ de água tratada - a partir do modelo empírico expresso pela Equação 1 , e a concentração de sólidos no lodo também tiveram alguma importância na previsão da área para desaguamento do lodo. A variação em torno do coeficiente $\mathrm{K}_{2}$ foi assumida entre valores mínimo e máximo obtidos da literatura (REALI, 1999), segundo distribuição uniforme. As incertezas, neste caso, podem ser atribuídas à incerteza verdadeira, decorrente do desconhecimento da relação entre sólidos suspensos totais e turbidez da água bruta no caso específico da ETA UFV. Isso significa que a investigação, caso a caso, dessa relação tende a reduzir a incerteza sobre essa variável e, consequentemente, aumentar a confiabilidade da estimativa de demanda de área dos leitos de secagem. Para a variável "concentração de sólidos", apenas a margem de segurança de $25 \%$ em torno de dados pontuais da estação foi utilizada para computar a variabilidade associada a ela. Aqui também se está perante incertezas verdadeiras, portanto, reduzíveis por meio de investigação.

No caso da vazão, os valores que definiram a distribuição triangular adotada (mínimo, máximo e valor de maior incidência) e, assim, sua variabilidade foram baseados em planilhas de registros diários da ETA UFV. Portanto, são dados confiáveis. No entanto, resultados diferentes podem advir de situações em que as variações de vazão da ETA sejam diferentes. 


\section{CONCLUSÕES}

De forma talvez pioneira, apresenta-se aqui um estudo de caso de dimensionamento de leito de secagem de lodo de ETA com base em modelagem probabilística, isto é, levando em consideração incertezas em torno de variáveis de entrada do modelo de dimensionamento. Os resultados, expressos em termos de distribuição de probabilidades, permitem flexibilidade na tomada de decisão, de acordo com aspectos técnicos e econômicos. O exercício aqui desenvolvido teve como base formulações empíricas disponíveis na literatura, cujas variáveis de entrada se encontram referendadas em bancos de dados de monitoramento da ETA em questão e outras, apenas em dados de literatura. Sugere-se, pois, que refinamentos futuros da técnica e dos modelos aqui empregados tenham por base, ao máximo possível, dados de campo e específicos de cada ETA em análise.

\section{REFERÊNCIAS}

BATISTA, L.A.; CABRAL, V.A.L. Ensaios com lodo do decantador da ETA UFV: caracterização, desaguamento em leito de secagem e possibilidades de aproveitamento. Projeto Final de Curso, Graduação em Engenharia Ambiental, Universidade Federal de Viçosa, Viçosa-MG, 2011.

CORDEIRO, J.S. Remoção natural de água de lodos de ETAs utilizando leitos de secagem e lagoas de lodo. In: REALI, M.A.P. (coordenador). Noções gerais de tratamento e disposição final de lo- dos de estações de tratamento de água. 240p. Projeto PROSAB. Rio de Janeiro: ABES, 1999.

KAWAMURA, S. Integrated Design of Water Treatment Facilities. New York: John Wiley \& Sons apud REALI, M.A.P. (coordenador). Noções gerais de tratamento e disposição final de lodos de estações de tratamento de água. 240p. Projeto PROSAB. Rio de Janeiro: ABES, 1999.

MORGAN, M. G.; HENRION, M. Uncertainty: a guide to dealing with uncertainty in quantitative risk and policy analysis. $325 \mathrm{p}$. Cambridge: Cambridge university press, 2003.

PALISADE CORPORATION. Manual do usuário. aRisk. AddIn do Microsoft ${ }^{\circledR}$ Excel para simulação e análise de riscos, versão 5.5, 2009.

REALI, M.A.P. (coordenador). Noções gerais de tratamento e disposição final de lodos de estações de tratamento de água. 240p. Projeto PROSAB. Rio de Janeiro: ABES, 1999.

RICHTER, C.A. Tratamento de lodos de estações de tratamento de águas. 102p. São Paulo: Editora Edgard Blücher, 2001.

SARON, A.; LEITE, V.M.B. Quantificação de lodo em estação de tratamento de água. In: $21^{\circ}$ Congresso Brasileiro de Engenharia Sanitária, João Pessoa. Anais eletrônicos... João Pessoa: ABES, 2003.

SOUZA, F.G.C.; CORDEIRO, J.S. Quantificação de sólidos em estação de tratamento de água convencional de ciclo completo com decantador de alta taxa. In: $23^{\circ}$ Congresso Brasileiro de Engenharia Sanitária, Campo Grande-MS. Anais eletrônicos... Campo Grande: ABES, 2005.

SPIEGEL, M. R.; tradução e revisão técnica: CONSENTINO P. Estatística. 643 p. $3^{\mathrm{a}}$ ed. São Paulo: Makron Books, 1993. 